ないかと言ら結果を与え，係数はよいが指数は整合性が よくないと言ら例は見当らなかったことを付け加えてお きたい。

最後に, 2. で誘導した関係式は均一な系についてのも のであるが，3. では均一系および不均一系で測定した実 験式を組合せてその整合性を検討した。不均一な系で測 定した実験式は分子量分布の影響を考虑することが必要 であるが，この問題については別の機会に報告する予定 である。

付 記：本研究の大要惊分子学会第 9 回年次大会 $(1960$ 年 5 月)に発表した。

$$
\text { 文献 }
$$

1) L. Mandelkern, W. R. Krigbaum, H. A. Scheraga and P. J. Flory: J. Chem. Phys., 20, 1392(1952)

2) R. Shimha: J. Chem. Phys., 13, 188(1945)
3) P. Outer, C. Carr and B. Zimm: J. Chem. Phys., 18, $830(1950)$

4）山田信夫：通研研究実用化報告, 8, 1257 (1959)

5) A. F. Schick and S. J. Singer: J. Phys. Colloid Chem., 54, 1028(1950)

6) 山田信夫, 松田英臣 : 第 8 回高分子学会年次大会 講演 (1959)

7) P. J. Flory: "Principles of Polymer Chemistry" (1953)

8) S. Newman and F. Eirich: J. Colloid Sci., 5, $541(1950)$

9) J. Bischoff and V. Desreux: J. Polymer Sci., 10, 437 (1953)

10) S. N. Chinai, J. D. Matlack, A. L. Resnick and R. J. Samuels: J. Polymer Sci., 17, 391 (1955)

11) M. Kurata, H. Yamakawa and H. Utiyama : Makromol. Chem., 34, 139(1959)

\title{
The Studies of Molecular Weight Distribution and Properties of Dilute Solutions
}

\section{Molecular Weight Dependence of the Hydrodynamic Properties of Polymer Solutions \\ By Nobuo Yamada*, Hideomi Matsuda* and Haruo Nakamura*}

The dependence of intrinsic viscosity of sedimentation constant and diffusion constant upon molecular weight, may be given by $[\eta]=K_{I} M^{\alpha}, S_{0}=K_{I I} M^{\beta}$ and $D_{0}=K_{I I I} M^{-} \gamma$ respectively. Then, the relationships among each group of the parameters $K_{I}, K_{I I}, K_{I I I}$ and $\alpha, \beta, \gamma$ can be obtained through use of the Flory-Fox theory for intrinsic viscosity, Svedberg's equation for sedimentation and Einstein's equation for diffusion respectively, making use of these relationships the experimental values of parameters were examined for a few polymer-solvent systems.

\section{第 4 報 実測された分子量分布の検討}

(1960 年 12 月 27 日受理)

山田信夫**.松田英臣**・中村晴雄**

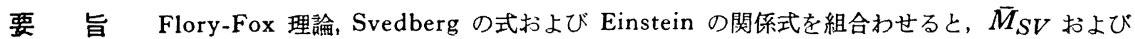
$\bar{M}_{D V}$ なる平均分子量が得られる。さらに $\bar{M}_{w}, \bar{M}_{n}$ および第 1 報, 第 2 報で述べた $\bar{M}_{S D}$ なる平均値を用 いて，沈降速度法抒よび抎散法で求めた分子量分布曲線の妥当性を確めるために，これらの分子量の実測做と 分布曲線からの計算値を比較検討した。
\end{abstract}

\section{1. 緒言}

前報では沈降扔よび拡散測定から分子量分布曲線を 求める際汇必要とされる沈降則（沈降定数と分子量の関 倸)，抎散則 (抎散定数と分子量の関係) のパラメーター

\begin{abstract}
および溶液論において問題とされる粘度則（極限粘度数 の分子量依存性）のパラメーターの相対的妥当性を検証 する関係式を導き, ポリスチレン-MEK および PMMAMEK で整合性のよいパラメーターを得た。

この論文では,このょうにして得た正確なパラメータ
\end{abstract}

* Electrical Communication Laboratory, Nippon Telegraph and Telephone Pubric Corporation (1551 Kichijoji, Musashino, Tokyo)

** 日本電信電話公社電気通信研究所 (東京都武蔵野市吉祥寺 1551) 
一を用いて沈降定数および拡散定数の重量分布曲線を分 子量分布曲線に変換したとき, 果してその分子量分布曲 線が妥当なものであるか否かを検討する。

一般に, 分子量分布の信賴性を確める一つの方法とし て平均分子量の実測值と分子量分布曲線から計算された 平均值を比較することが考えられる。

そこで本報告では, Svedberg の近似式, Einstein の 式および Flory-Fox 理論を用いて $\bar{M}_{S V}, \bar{M}_{D V}$ なる平 均分子量の性質を明確にし， $\bar{M}_{w}, \bar{M}_{n}$ および第 1 報，第 2 報 で述べた $\bar{M}_{S D}$ と共にそれらの実測值と分子量分 布からの計算值を比較して分子量分布曲線の信頼性を検 討した。

\section{2. 平均分子量 $\left(\bar{M}_{S V}, \bar{M}_{D V}\right)$ の性質}

Shimha ${ }^{1)}$ の提出した沈降定数掞よび拡散定数の分子 量依存性を表わ寸関係式が分子量分布のない系に対して も成立すると仮定する。

$$
\begin{aligned}
& S_{i}=K_{I I} M_{i}^{\beta} \\
& D_{i}=K_{I I I} M_{i}^{-\gamma}
\end{aligned}
$$

一方, 沈降測定から 沈降図形を Gralén ${ }^{2)}$ の方法で解 析すると沈降定数の重量分布曲線が得られる。その重量 平均值を $\bar{S}_{w}$ で表わすと，

$$
\bar{S}_{w}=\frac{\sum_{i} S_{i} w_{i}}{\sum_{i} w_{i}}
$$

ここに $w_{i}$ は沈降定数 $S_{i}$ の分子種の 重量である。

式と（3）式を組合せると，次の（4) 式になる。

$$
\bar{S}_{w}=K_{I I}\left(\bar{M}_{S}\right)^{\beta}
$$

（4）式の $\bar{M}_{S}$ は（5）式で記述される平均分子量で，こ れは粘度平均分子量と全く同じ形式の平均值である。

$$
\bar{M}_{S}=\left(\frac{\sum_{i} M_{i} \beta w_{i}}{\sum_{i} w_{i}}\right)^{\frac{1}{\beta}}
$$

次に抎散曲線をモーメント法で計算すると，拡散定数 の重量平均値を与えることが知られている。

$$
\bar{D}_{w}=\frac{\sum_{i} D_{i} w_{i}}{\sum_{i} w_{i}}
$$

ここに $w_{i}$ は拡散定数 $D_{i}$ をもつ分子種の重量である。 (2) 式と (6) 式を組合わせると (4) 式と全く同じ形式の 次の (7) 式が得られ，(7) 式の $\bar{M}_{D}$ は (8) 式で与えら れる平均分子量である。

$$
\begin{array}{r}
\bar{D}_{w}=K_{I I I}\left(\bar{M}_{D}\right)^{-\gamma} \\
\bar{M}_{D}=\left(\frac{\sum_{i} M_{i}^{-} \gamma w_{i}}{\sum_{i} w_{i}}\right)^{-\frac{1}{\gamma}}
\end{array}
$$

粘度則については均一系では (9) 式で, 不均一系では (10) 式で与えられる。

$$
\begin{aligned}
& {[\eta]_{i}=K_{I} M_{i}^{\alpha}} \\
& {[\eta]=K_{I}\left(\bar{M}_{V}\right)^{\alpha}}
\end{aligned}
$$

次に, Svedberg の式と Flory-Fox 理論を組合わせる と, 沈降定数 $S_{i}$, 極限粘度数 $[\eta]$ 抢よび分子量 $M_{i}$ の間 に次の (11) 式で表わされる関係式が知られている8 。

$$
S_{i}[\eta]^{1} M_{i} i^{-2}=\frac{\Phi_{3}^{3} P^{-1}(1-\bar{v} \rho)}{\eta_{0} N}
$$

上式で $\Phi, P$ は Flory の普遍定数, $\bar{v}, \rho, \eta_{0}, N$ はそれ ぞれ溶質の部分比容, 溶媒の密度, 溶媒の粘度およびア ボガドロ数である。（11）式は均一系で成立する関倸式 であるので, 沈降定数および極限粘度数としてそれぞれ $\bar{S}_{w 0}$ および $[\eta]$ を用いた場合計算される平均分子量を $\bar{M}_{S V}$ で表わすと

$$
\bar{M}_{S V}=\left(P^{-1} \Phi_{3}^{1}\right)^{-\frac{3}{2}} N^{\frac{3}{2}}\left(\frac{\bar{S}_{w} \eta_{0}}{1-\bar{v} \rho}\right)^{\frac{3}{2}}[\eta]^{\frac{1}{2}}
$$

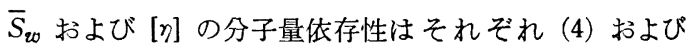
(10) 式で表わされるので, それらを（12）式に代入する と

$$
\bar{M}_{S V}=K^{-\frac{3}{2}}\left(\bar{M}_{S}\right)^{\frac{3 \beta}{2}}\left(\bar{M}_{V}\right)^{\frac{\alpha}{2}}
$$

ここに $K$ は分子量に 無関係な定数で前報で述べたよう に均一な系では

$$
K=\left(P^{-1} \Phi_{\mathfrak{\jmath}}\right)\left(\frac{1-\bar{v} \rho}{\eta_{0} N}\right) K_{I I^{-1}} K_{I^{-}}^{-\grave{\jmath}}=1
$$

となる。また不均一な系でも $K=1$ が成立するはずであ る。それは (1) 式と (4) 式, (9) 式と（10) 式を比較する と両式とも分子量の意味は異なるが, 同じパラメーター によって表示されているからである。したがって次式が 成立する。

$$
\begin{aligned}
\bar{M}_{S V} & =\left(\bar{M}_{S}\right)^{\frac{3}{2}-}\left(\bar{M}_{V}\right)^{\frac{\alpha}{2}} \\
& =\left(\frac{\sum_{i} M_{i} \beta w_{i}}{\sum_{i} w_{i}}\right)^{\frac{3}{2}}\left(\frac{\sum_{i} M_{i}^{\alpha} w_{i}}{\sum_{i} w_{i}}\right)^{\frac{1}{2}}
\end{aligned}
$$

$\bar{M}_{D V}$ なる平均分子量も 全く同じようにして与えられ 
る。すなわち，拡散定数と摩擦係数の間の関係式として 知られている Einstein の式と Flory-Fox 理論を組合わ せると

$$
\left(M_{i}\left[\eta_{i}\right]_{i}^{3} D_{i}=\left(P^{-1} \Phi_{3}^{\mathfrak{a}}\right)\left(\frac{k T}{\eta_{0}}\right)\right.
$$

が遒かれている。ここに $k, T$ はそれぞれボルッマン定 数および絶対温度である。(15) 式の $D_{i},[\eta]_{i}$ の代わりに $\bar{D}_{w},[\eta]$ を用いた場合の平均分子量を $\bar{M}_{D V}$ で表わすと

$$
\bar{M}_{D V}=\left(\frac{k T}{\eta_{0}}\right)^{8}\left(P^{-1} \Phi_{\zeta}\right)^{3}\left(\bar{D}_{z v}\right)^{-3}[\eta]^{-1}
$$

したがって $\bar{M}_{D V}$ の形式は (7), (10), (16) 式から与え られる。

$$
\begin{aligned}
\bar{M}_{D V} & =\left(\bar{M}_{D}\right)^{8} r\left(\bar{M}_{V}\right)^{-\alpha} \\
& =\left(\frac{\sum_{i} M_{i}{ }^{-} r w_{i}}{\sum_{i} w_{i}}\right)^{-3}\left(\frac{\sum_{i} M_{i} \alpha w_{i}}{\sum_{i} w_{i}}\right)^{-1}
\end{aligned}
$$

な扔小林")はすでに粘度則のパラメーター $\alpha$ を用いて $\bar{M}_{S V}, \bar{M}_{D V}$ なる平均分子量を次のごとくに定義してい るが,これは $\beta=(2-\alpha) / 3, \gamma=(\alpha+1) / 3$ を(14), (17) 式 に代入すれば得られる。

$$
\begin{aligned}
& \bar{M}_{S V}=\left(\frac{\sum_{i} M_{i}^{\frac{2-\alpha}{3}} w_{i}}{\sum_{i} w_{i}}\right)^{\frac{3}{2}}\left(\frac{\sum_{i} M_{i} \alpha w_{i}}{\sum_{i} w_{i}}\right)^{\frac{1}{2}} \\
& \bar{M}_{D V}=\left(\frac{\sum_{i} M_{i}^{\frac{(-1-\alpha)}{3}} w_{\imath}}{\sum_{i} w_{i}}\right)^{-3}\left(\frac{\sum_{i} M_{i} \alpha w_{i}}{\sum_{i} w_{i}}\right)^{-1}
\end{aligned}
$$

\section{3. 平均分子量の計算}

2 種類の市販ポリスチレン $(\mathrm{A}, \mathrm{B})$ の MEK 溶液の 沈降，拡散，光散乱および粘度測定を行ない，沈降測定 に対しては Gralén の方法2)を用いて沈降定数の重量分 布曲線を得，また拡散測定からは試料 A については拡 散定数の重量分布函数として Gram-Chalier の A 型級 数, 試料 B に対しては分子量の重量分布函数として Gralén の分布函数5)を纳定して拡散定数の重量分布函 数を算出した。そしてこ机らを第 3 報で検討して妥当性 のあることの知られた沈隆則㧍よび拡散則

$$
\begin{aligned}
& S_{i}=4.09 \times 10^{-15} M_{i}^{0.47} \\
& D_{i}=3.43 \times 10^{-4} M_{i}^{-0.53}
\end{aligned}
$$

を用いて分子量分布曲線に変換した。その結果を Fig. 1 および Fig. 2 に示す。これらの分子量分布曲線を用い て種々の平均分子量を計算し, Table 1 および Table 2

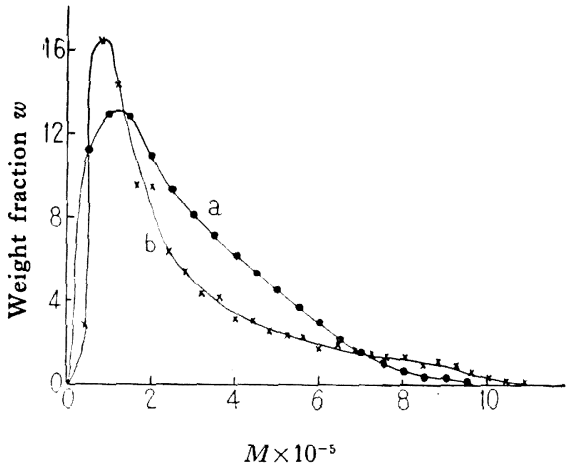

Fig. 1 Molecular weight distribution curves of sample A obtained from sedimentation (curve a) and diffusion (curve b)

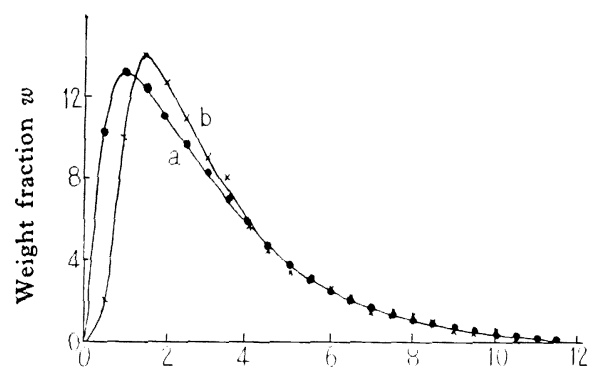

$M \times 10^{-5}$

Fig. 2 Molecular weight distribution curves of sample $B$ obtained from sedimentation (curve a) and diffusion (curve b)

Table 1 Comparison the observed values with those calculated from molecular weight distribution curves (Fig. 1) for the various average molecular weight

\begin{tabular}{l|c|c|c}
\hline & Observed & \multicolumn{2}{|c}{ Calculated values } \\
\cline { 3 - 4 } & values & $\begin{array}{c}\text { S-distribu- } \\
\text { tion** }\end{array}$ & $\begin{array}{c}\text { D-distribu- } \\
\text { tion*** }\end{array}$ \\
\hline $\bar{M}_{w} \times 10^{-5}$ & 2.90 & 2.81 & 2.90 \\
$\bar{M}_{n} \times 10^{-5}$ & $1.80^{*}$ & 1.59 & 1.60 \\
$\bar{M}_{S D} \times 10^{-5}$ & 2.65 & 2.12 & 2.11 \\
$\bar{M}_{S V} \times 10^{-5}$ & 2.40 & 2.35 & 2.36 \\
$\bar{M}_{D V} \times 10^{-5}$ & 4.18 & 1.73 & 1.69 \\
$\bar{M}_{V} \times 10^{-5}$ & 1.80 & 2.55 & 2.57 \\
$\bar{M}_{S \times 10^{-5}}$ & 2.37 & 2.48 & 2.48 \\
$\bar{M}_{D} \times 10^{-5}$ & 2.75 & 1.85 & 1.83 \\
\hline
\end{tabular}

* The value obtained from measurement of osmotic pressure by A. Kotera and K. Takamizawa (Tokyo University of Education)

** Curve (a) of Fig. 1

*** Curve (b) of Fig. 1 
Table 2 Comparison the observed values with those calculated from molecular weight distribution curves (Fig. 2) for the various average molecular weights

\begin{tabular}{l|c|c|c}
\hline \hline & Observed & \multicolumn{2}{|c}{ Calculated values } \\
\cline { 3 - 4 } & values & $\begin{array}{c}\text { S-distribu- } \\
\text { tion* }\end{array}$ & $\begin{array}{c}\text { D-distribu- } \\
\text { tion** }\end{array}$ \\
\hline $\bar{M}_{w} \times 10^{-5}$ & 3.29 & 2.92 & 3.18 \\
$\bar{M}_{n} \times 10^{-5}$ & - & 1.59 & 2.13 \\
$\bar{M}_{S D \times 10^{-5}}$ & 2.17 & 2.14 & 2.43 \\
$\bar{M}_{S V} \times 10^{-5}$ & 2.17 & 2.40 & 2.48 \\
$\bar{M}_{D V} \times 10^{-5}$ & 2.14 & 1.71 & 2.34 \\
$\bar{M}_{V \times 10^{-5}}$ & 2.10 & 2.61 & 2.94 \\
$\bar{M}_{S} \times 10^{-5}$ & 1.93 & 2.53 & 2.53 \\
$\bar{M}_{D} \times 10^{-5}$ & 1.91 & 1.85 & 2.35 \\
\hline
\end{tabular}

* Curve (a) of Fig. 2

** Curve (b) of Fig. 2

に示した。

分子量分布曲線からの計算值はすべて $\alpha, \beta, \gamma$ をそれ ぞれ $0.58,0.47,0.53$ として算出し， $\bar{M}_{S D}$ は第 1 報 および第 2 報の定義式に従って求めた。

一方, 実測値については $\bar{M}_{w}$ は光散乱の測定から, $\bar{M}_{S D}, \bar{M}_{S V}, \bar{M}_{D V}$ はそれぞれ $\bar{S}_{w}, \bar{D}_{w},[\eta]$ の測定值 を(20)，(12)，(16) 式に入れて計算した。

$$
\bar{M}_{S D}=\frac{\bar{S}_{w} k N T}{\bar{D}_{w}(1-\bar{v} \rho)}
$$

また， $\bar{M}_{V}, \bar{M}_{S}, \bar{M}_{D}$ の実測值と言うのはそれぞれ (21)，(18)，(19) 式に $[\eta] ， \overline{S_{w}}, \bar{D}_{w}$ の測定值を代入し て求めた。

$$
[\eta]_{i}=3.9 \times 10^{-4} M_{i}^{0.58}
$$

なお，ポリスチレン $\mathrm{A}$ の測定された $\overline{S_{w}}, \overline{D_{w}},[\eta]$ は それぞれ $13.74 \times 10^{-13}(\mathrm{sec}) ， 4.496 \times 10^{-7}\left(\mathrm{~cm}^{2} / \mathrm{sec}\right)$, $0.435(100 \mathrm{cc} / \mathrm{g})$ でポリスチレン B についてはそれぞ れ $12.46 \times 10^{-18}(\mathrm{sec}), 5.448 \times 10^{-7}\left(\mathrm{~cm}^{2} / \mathrm{sec}\right)$ および $0.477(100 \mathrm{cc} / \mathrm{g})$ であった。

\section{4. 考察}

Fig. 1 および Fig. 2 の沈降抒よび拡散測定から求め られた分子量分布曲線にはかなりの差異がある。すなわ ち試料 A (Fig. 1) は共に分子量 10 万前後にピークが あるがその高さが異なり，分子量が増すに従って $D$ 分布 (拡散測定から得られた分子量分布) は急激に減少するの に対し, $S$ 分布(沈降測定から得られた分子量分布)はゆ るやかである。一方 Fig. 2 の試料 B では曲線の形は よく似ているが，ピークの位置が $S$ 分布の方が $D$ 分布
より低分子側にある。このように同一試料に対しても測 定方法を異にすると，汃なり異なる分子量分布曲線が得 られる。このことは測定方法に固有な解析方法の不備拉 よび実験誤差のためと思われる。それゆえに得られた分 子量分布の妥当性を検討することが必要である。この検 証のために Table 1 抢よび Table 2 の種々の平均分子 量に対する実測值と分子量分布曲線からの計算值との比 較を行なった。

Table 1 の試料 A では $\bar{M}_{w}$ および $\bar{M}_{n}$ の実測值は $S$ 分布および $D$ 分布の計算値と非常によく一致してい る。また $\bar{M}_{S V}$ は非常によく一致しており， $\bar{M}_{S D}$ は一 応満足すべき結果である。これに対して $\bar{M}_{D V}$ の実測值 々計算值ははなはだしく相違しており，実測值 41.8 万 は異常に大きい。さらに $\bar{M}_{V}$ および $\bar{M}_{D}$ の実測值と分 布曲線からの計算值の一致はよくない。この両者の不一 致, ことに $\bar{M}_{V}$ の実測值計計算值より小さく, $\bar{M}_{D}$ は 逆の傾向をもった不一致を示していることは $\bar{M}_{D V}$ の平 均值の性質 (17) 式加ら予想されるように $\bar{M}_{D V}$ の異常 な相違をもたらしている。

一方, Frisch ら ${ }^{6)}$ によれば $\bar{M}_{v}(r)=\left[\int_{0}^{\infty} M^{r} f(M) d M\right]^{\frac{1}{r}}$ で表わされる平均分子量 $\bar{M}_{v}(r)$ は $r>S$ のときには $\bar{M}_{v}(r) \geq \bar{M}_{v}(S)$ を満足する。Flory-Fox 理論によれば (9) 式の $\alpha$ は 0.5 0.8, したがって (1) 式の $\beta$ は 0.4 0.5 , (2) 式の $\gamma$ は 0.5 0.6 なる籁囲の数值であるこ とを考慮すれば, 次の (23) で表わされる大小関係が成 立するはずである。

$$
\bar{M}_{w} \geq \bar{M}_{V} \geq \bar{M}_{S} \geq \bar{M}_{D} \geq \bar{M}_{n}
$$

ここで等号は均一試料に対して成り立ち, さらに $\alpha=$ $\beta=1 / 2$ すなわち $\theta$ 点で $\bar{M}_{V}=\bar{M}_{S}$ を満足する。したが って実測值 $\bar{M}_{V}$ の 18.0 万は過小で, $\bar{M}_{D}$ の 27.5 万 は過大と思われる。これは $\bar{M}_{V}$ および $\bar{M}_{D}$ を算出した (21) 式㧍よび (19) 式にまだ問題が残されているかある いは [ク] および $\bar{D}_{w}$ の測定值の誤差のためと思われる。

次に Table 2 の試料 B について検討する。 $\bar{M}_{w}$ は実 測值と分子量分布曲線からの計算值がかなりよく一致し ている。これに対して $\bar{M}_{S D} \sim \bar{M}_{D}$ の各平均分子量は $S$ 分布が $D$ 分布に比べてわずかに小さい值を与えている ことは両者の分子量分布曲線の相違に基くものと思われ る。しかしこれらの平均分子量の実測值との一致の程度 は一応满足されている。

このように, 得られた分子量分布曲線の信頼性を確め るために, 種々の平均分子量の実測値と計算值を比較し て検討したが，試料 $\mathrm{A}$ では $S$ 分布と $D$ 分布の各平均 值はほとんどよく一致して抒り，実測值 $\bar{M}_{w}, \bar{M}_{n}$ との一 致もきわめてよいにもかかわらず両者の分布曲線はかな り相違しているが，そのいずれがより妥当性のある分布 
曲線であるかということは判別しがたい。試料 B につ いては $S$ 分布と $D$ 分布は非常によく曲線の形が類似し ているので， $\bar{M}_{n}$ の正確な実測值があれば，ある程度両 者の信頼性を判別することができるるのと考えられる。

したがって沈降速度法扔よび昖散法によって求められ た分布曲線 $(S$ 分布および $D$ 分布) のいずれが妥当な ものであるかといらことは，さらに $\bar{M}_{w}$ および $\bar{M}_{n}$ の 実測值の信頼性を高めるとともに，それぞれの測定法に 固有な解析法をさらに詳細に検討しなければならないと 思われる。

以上のごとく，各平均分子量の測定值自体の精度の問 題はあるが，現状では $S$ 分布は $\bar{M}_{w}, \bar{M}_{n}$ および $\bar{M}_{S V}$ (あるいは $\left.\bar{M}_{S D)}\right), D$ 分布では $\bar{M}_{w}, \bar{M}_{n}$ おょよび $\bar{M}_{D V}$

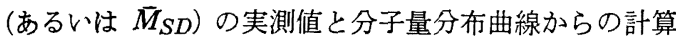

值を比較検討すれば, 分子量分布曲線の妥当性は一応保 証し得るように思われる。

付 記：本研究の大要は高分子学会第 9 回年次大会 $(1960$ 年 5 月）に発表した。

$$
\text { 文献 }
$$

1) R. Shimha: J. Chem. Phys., 13, 188(1945)

2) N. Gralén and G. Lagermalm: J. Phys. Chem., 56, 514(1952)

3) L. Mandelkern, W. R. Krigbaum, H. A. Scheraga and P. J. Flory: J. Chem. Phys., 20, $1392(1952)$

4) H. Kobayashi : J. Polymer Sci., 39, 369 (1959)

5) N. Gralén: Kolloid Z., 95, 188(1941)

6) H. L. Frisch and J. L. Lundberg: J. Polymer Sci., 37, 123(1959)

\section{The Studies of Molecular Weight Distribution and Properties of Dilute Solutions}

IV. Discussions of the Molecular Weight Distribution obtained by the Sedimentation Velocity and Diffusion Methods

By Nobuo Yamada*, Hideomi Matsuda* and Haruo Nakamura*

The average molecular weights $\bar{M}_{S V}$ and $\bar{M}_{D V}$ are obtained by combining Flory-Fox theory of intrinsic viscosity, with Svedberg's equation for sedimentation and with Einstein's equation for diffusion, respectively. For the purpose of examining the validity of the molecular weight distribution curves obtained by the sedimentation velocity and diffusion methods, the observed values for the following average molecular weights are compared with those calculated from the distribution curves; weight average molecular weight $\bar{M}_{w}$, number average molecular weight $\bar{M}_{n}$, and $\bar{M}_{S V}, \bar{M}_{D V}$ and $\bar{M}_{S D}$ (defined in part I and II of our studies).

第 5 報 沈降および拡散測定による分子量分布の測定

(1960 年 12 月 27 日受理)

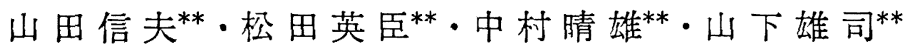

要 旨 分子量と沈降定数および分子量と拡散定数との関係式が知られていない場合に, 沈降定数と拡 散定数のそれぞれの重量分布を組合わせ，Svedberg の式を使って，分子量分布を求める方法を提出し，これ をポリスチレン-MEK の系について適用し，かなり整合性のある分子量分布曲線を得た。

1. 緒言

高分子の 分子量分布を測定するのに，沈降速度法お よび拡散法は有力な方法であり，すでにわれわれもポリ スチレンについてそれらの方法で分子量分布を測定し
$た^{1,2)}$ 。

しかしそのいずれの場合にも，原理的には分子量に分 布のない系に対する沈降定数 $S_{i}$ および拡散定数 $D_{i}$ と 分子量 $M_{i}$ との関倸

$$
S_{i}=K_{I I} M_{i}^{\beta}
$$

* Electrical Communication Laboratory, Nippon Telegraph and Telephone Public Corporation (1551 Kichijoji Musashino, Tokyo)

** 日本電信電話公社電気通信研究所(東京都武蔵野市吉祥寺 1551) 